Original article

\title{
Association of erythrocyte sedimentation rate and C-reactive protein and clinical findings with HLA- DQ8 allele in Rheumatoid Arthritis patients
}

\author{
Karim Mowla ${ }^{1}$, Najmeh Ahmadzadeh Goli ${ }^{2}$, Reza Kazemi Nezhad ${ }^{3}$, Zeinab Deris Zayeri ${ }^{1}$, \\ Mehrdad Dargahi Mal-Amir ${ }^{1}$, Elham Rajaei ${ }^{1}$ \\ ${ }^{1}$ Ahvaz Jundishapur University of Medical Sciences, Ahvaz, Iran \\ ${ }^{2}$ Shiraz University of medical science. Shiraz. Iran \\ ${ }^{3}$ Sahid Chamran University of Ahvaz, Ahvaz, Iran
}

Received 1 October 2017, Revised 11 October 2018, Accepted 21 November 2018

(C) 2018, Mowla K., Goli N.A., Kazemi Nezhad R., Zayeri Z.D., Dargahi Mal-Amir M., Rajaei E.

(C) 2018, Russian Open Medical Journal

\begin{abstract}
Background - Rheumatoid arthritis (RA) is an inflammatory, autoimmune disease induced by certain auto-antigens. HLADRB1*0401 allele has a significant relationship with RA incident. Additionally, DQ $31 * 0301, * 302$ (DQ8), *303, and *304 can increase RA risk especially in DQA ${ }^{*} 0301$ and *302 coincident. Recent studies suggest that distribution of this allele is different in various populations Material and Methods - 70 patients and 70 healthy controls were analyzed for human leukocyte antigen (HLA) allele by specific primerpolymerase chain reaction (SSP-PCR) method. Patients were evaluated in terms of ESR and CRP. Data analysis was performed in SPSS V.17. Results - HLA-DQ8 allele was significantly more frequent in RA patients compared to control $(P<0.0001)$. However, no significant relationship was observed between increased ESR ( $P=0.527)$, CRP $(P=0.505)$, and mean counts of arthritic $(P=0.691)$ and tender joints $(\mathrm{P}=0.669)$ among the patients who were carriers of HLA-DQ8.

Conclusion - There is a significant association between RA and HLA-DQ8 allele, this allele can increase susceptibility to RA. These findings might relate to the ethnical variations of RA patients but we couldn't find a significant association between CRP and ESR with HLA-DQ8. We recommend to add specific inflammatory markers to CRP as well as assess ESR in larger sample sizes to obtain accurate results.
\end{abstract}

Keywords: C-reactive protein, erythrocyte sediment rate, HLA-DQ8, rheumatoid arthritis.

Cite as Mowla K, Goli NA, Kazemi Nezhad R, Zayeri ZD, Dargahi Mal-Amir M, Rajaei E. Association of erythrocyte sedimentation rate and C-reactive protein and clinical findings with HLA-DQ8 allele in Rheumatoid Arthritis patients. Russian Open Medical Journal 2019 ; 8: e0108.

Correspondence to Elham Rajaei. E-mail: elhamrj@gmail.com.

\section{Introduction}

Rheumatoid arthritis (RA) is an autoimmune, inflammatory disease that mostly affects diarthrodial joints and is characterized by synovial tissue inflammation, pannus formation, and bone erosion [1, 2]. Since the synovial joint is considered as the primary target organ in RA, no clear evidence proves whether macro-molecules in the cartilaginous tissue, bone, or synovium could act as a preferential auto-antigen in RA [3].

RA has unknown etiology, and scientists believe environmental and genetic factors are involved in pathogenesis of RA [4]. RA could be initiated with specific antigens in genetically susceptible individuals. Among genetic components, the major histocompatibility complex (MHC) might be the most significant predisposing factor in RA $[5,6]$. However, MHC is not the only factor which can induce RA through mediating the leukocyte interactions $[7,8]$. These antigens lead to T-cells activation. MHCs associate to specific molecules [9-11]. Recently, several non-MHC loci have been identified to contain the genes that are possibly involved in disease mechanisms $[12,13]$.
Several studies indicate complex of genes encode MHC proteins. Human leukocyte antigen (HLA) system could be involved in RA incident through certain HLA alleles [14-16]. Recently numbers of MHC allele subtypes are identified by polymerase chain reaction (PCR) method [17].

Despite noticeable variations in different ethnic groups, individuals carrying HLA-DRB1 alleles $\left(* 0101, *^{*} 0401, *^{*} 0404\right.$, and $\left.{ }^{*} 0405\right)$ are at higher risk of developing RA (18-20). Polymorphisms are noticeable in antigen-binding sites of MHCs, while polymorphisms in HLA-DR are confined to DR $\beta$ chain (DRB1/3/4/5 genes), and the DR $\alpha$ chain is considered to be essentially monomorphic.

Despite some HLA disease associations, there is inadequate information regarding the nature of HLA-bound self-peptides, which of these HLAs are involved in the autoimmunity of RA. Restriction of the development of specific immune intervention strategies is aimed at the inhibition or prevention of such deleterious immune responses. Nevertheless, RA is arguably one of the best-described systems for comprehending the genetic associations between HLA-II alleles, autoimmunity, and presentation of self-peptides [21, 22]. 
Table 1. More details of the patients

\begin{tabular}{ccccc}
\hline Groups & Number & Mean Age & Arabic & Non-Arabic \\
\hline Patient & 70 & 43.84 & $66.2 \%$ & $33.8 \%$ \\
Control & 70 & 43.75 & $70.76 \%$ & $29.23 \%$ \\
\hline
\end{tabular}

Table 2. List of the primers used

\begin{tabular}{lrc}
\hline Primer & \multicolumn{1}{c}{ sequence } & $\begin{array}{c}\text { PCR product } \\
\text { size }(\mathrm{bp})\end{array}$ \\
\hline Control positive forward & 5'CACTCTTCGAGCCTTCCTTC-3' & 354 \\
Control positive reverse & 5'AGTCCGCCTAGAAGCATTTG-3' & 354 \\
0303 subtype forward & 5'-GACGGAGCGCGTGCGTCT-3' & 122 \\
0303 subtype reverse & 5'-CAGTACTCGGCGTCAGGCG-3' & 122 \\
0302 subtype forward & 5'-GACGGAGCGCGTGCGTCT-3' & 129 \\
0302 subtype reverse & 5'-CTGTCCAGTACTCGGCGG-3' & 129 \\
\hline
\end{tabular}

Table 3. Distribution of HLA-DQ8 allele between *RA patients and controls

\begin{tabular}{|c|c|c|c|c|}
\hline \multirow[t]{2}{*}{ Groups } & & \multicolumn{2}{|c|}{$D Q 8$} & \multirow[t]{2}{*}{ Total } \\
\hline & & Positive & Negative & \\
\hline \multirow[t]{4}{*}{ Patients } & Number & 40 & 25 & 65 \\
\hline & Percent & 61.5 & 38.5 & 100 \\
\hline & Percent of patients having the allele & 72.7 & 33.3 & 50 \\
\hline & $\begin{array}{l}\text { The percent of patients in the total } \\
\text { population of the study }\end{array}$ & 30.8 & 19.2 & 50 \\
\hline \multirow[t]{4}{*}{ Control } & Number & 15 & 50 & 65 \\
\hline & Percent & 23.1 & 76.9 & 100 \\
\hline & Percent of controls having the allele & 27.3 & 66.7 & 50 \\
\hline & $\begin{array}{l}\text { The percent of controls in the total } \\
\text { population of the study }\end{array}$ & 11.5 & 38.5 & 50 \\
\hline \multirow[t]{2}{*}{ Total } & Number & 55 & 75 & 130 \\
\hline & Percent & 42.3 & 55.7 & 100 \\
\hline
\end{tabular}

Table 4. ESR change among the patients

\begin{tabular}{ccccc}
\hline Total & Up to $100 / \mathrm{h}$ & Less than $100 \mathrm{~mm} / \mathrm{h}$ & $0-20 \mathrm{~mm} / \mathrm{h}$ & HLA-DQ8 \\
\hline 61.5 & 3.1 & 36.9 & 21.5 & Positive \\
38.5 & 1.5 & 20 & 16.9 & Negative \\
\hline
\end{tabular}

Table 5. CRP changes among the patients

\begin{tabular}{lc}
\hline The present in the patients & CRP range \\
\hline $50.8 \%$ & Negative \\
$18.5 \%$ & +1 \\
$12.3 \%$ & +2 \\
$18.5 \%$ & +3 \\
\hline
\end{tabular}

Recent studies have investigated the inheritance pattern of different HLA alleles in various populations and its impact on the distribution of RA. However, none of these studies have been focused on the relationship between HLA-DQ8 alleles and related markers of disease activity biomarkers such as C-reactive protein (CRP) and erythrocyte sedimentation rate (ESR), and arthritic and tender joints. We used CRP and ESR and HLA-DQ8 and arthritic tender joints in this study because HLA genes show a loss of sexand age-dependent changes and this gene has the strongest association with the additional risk of RA [23]. CRP is a better measure of disease activity than ESR because it is much more specific in disease activity [24]. However, we used both of these test to achieve more confident results and have more markers in measuring disease activity. This study designed due to the lack of related research, this study designed to evaluate the associations of HLA-DQ8 allele with erythrocyte sedimentation rate (ESR) and C-reactive protein (CRP) and clinical findings of RA focused on arthritic and tender joints as markers to evaluate therapeutic response in RA patients in Ahvaz city, Iran because there is no enough study in this field.

\section{Material and Methods \\ Patients}

This analytic epidemiological trial was conducted on 70 patients aged above16 years diagnosed with RA and 70 healthy (controls) at Imam Khomeini and Golestan hospitals in Ahvaz city, Iran. The control group consisted of healthy blood donors aged above 16 years who had no history of genetic or rheumatologic diseases. Inclusion criteria of the study were age of $>16$ years, scores of at least six in the EULAR 2010 criteria for RA diagnosis. Totally there were 49 female (75.5\%) and 6 male (24.6\%) participants in the study groups. Both study groups were matched in terms of age, gender, and ethnicity. Participants were selected via non-probability and convenience sampling. More details of the patients are described in Table 1. Sample size of the study was calculated at 70 subjects per each group using NCSS software for our statistical analysis.

\section{Blood DNA extraction}

DNeasy Blood \& Tissue Kits of Qiagen which used for rapid purification of total DNA of frozen blood. The DNeasy membrane combines the binding properties of a silica-based membrane with simple microspin technology or with the QIAGEN 96-Well-Plate Centrifugation System. DNA adsorbs to the DNeasy membrane in the presence of high concentrations of chaotropic salt, which remove water from hydrated molecules in solution. Buffer conditions in DNeasy Blood used to enable specific adsorption of DNA to the silica membrane and optimal removal of contaminants and enzyme inhibitors. Purification requires no phenol or chloroform extraction or alcohol precipitation, and involves minimal handling. Silica-membrane technology, in convenient spin-column or 96-well formats, ensures fast and reproducible DNA purification, eliminating the need for organic extraction and alcohol precipitation. Samples are first lysed using proteinase K. Buffering conditions are adjusted to provide optimal DNA-binding conditions and the lysate is loaded onto the DNeasy Mini spin column or the DNeasy 96 plate. During centrifugation, DNA is selectively bound to the DNeasy membrane as contaminants pass through. Remaining contaminants and enzyme inhibitors are removed in two efficient wash steps and DNA is then eluted in water or buffer. The purification procedures using DNeasy Mini spin columns. The DNeasy 96 Blood \& Tissue Kit used this kit prepare 96-well format using the QIAGEN 96-Well-Plate Centrifugation System. We used this kit because it was easy to use and the purification was high so we could gain high quality DNA.

\section{Primer designing \& polymerase chain reaction}

First of all, we look up our gene in NCBI to choose our gene firstly then the primer3 software (Denmark), to design the suitable primer in other word we used our base pair information to build a set of primers within the range of our gene and we arranged our primers in Table 2.

Then we checked our primer in RepeatMasker web site to be sure it is efficient enough. We chose reaction temperature considered to the concentration of $\mathrm{G}$ and $\mathrm{C}$ nucleotide and the temperature meant to be $70^{\circ} \mathrm{C}$. 


\section{Verification of HLA-DQ via single specific primer-polymerase chain reaction (SSP-PCR)}

In order to eliminate false negative results in PCR we used positive control and PCR products $\beta$-actin $354 \mathrm{bp}$ as internal control and housekeeping genes in each PCR procedure and we present our control positive in Table 2. (ESR)

C-reactive protein (CRP) and erythrocyte sedimentation rate

We used Rheumajet CRP Latex Agglutination Test Kit for the detection of C-reactive protein. In this kit CRP latex reagent consists of latex particles coated with C-reactive protein. In the presence of C-polysaccharide of levels greater than $6 \mathrm{mg} / \mathrm{L}$ in serum, the coated latex particles will agglutinate providing a visually observable reaction of antigen and antibody.

We used Erythrocyte sedimentation rate analysis model ESR20/ESR40 of BIOBASE brand to measure the ESR Measurement Range were described (1-140) $\mathrm{mm} / \mathrm{h}$ for this device and this device Loading Capacity is $20 / 40$ samples at same time and the reading time sat at 30 minutes.

\section{Statistical analysis}

Data analysis was performed in SPSS V.17 using Chi-square and independent T-test to determine the associations, and P-Value of less than 0.05 was considered significant based on the Fisher's exact test.

\section{Ethical considerations}

Written informed consent was obtained from all the participants prior to the study, and participation was free of charge. Moreover, participants were assured of confidentiality terms regarding their medical record information.

\section{Results}

Comparison of the frequency of HLA-DQ8 between RA patients and control subjects indicated that out of 65 RA patients, 40 cases (61.5\%) were carriers of HLA-DQ8, while this allele was identified in 15 subjects $(23.1 \%)$ of the control group. Totally, HLA-DQ8 was detected in $72.7 \%$ of the subjects in both study groups; whereas $27.3 \%$ of the subjects did not carry this allele. A statistically significant difference was observed between the study groups in this regard $(P<0.0001)$. Therefore, a significant association was deduced between the inheritance of HLA-DQ8 alleles and incidence of RA (Table 3).

Among the studied RA patients, rate of ESR was high in 40 cases (61.5\%), while it was relatively low in 25 cases (38.5\%). In female patients, ESR rate was higher than the values obtained from +10 age $/ 2$, and for male patients, it was considered more than the age/ 2 as increased. In this study, we considered the CRP increase equal to or higher than +1 in both genders, and CRP was reported to increase in 32 cases (49.2\%). Mean counts of the tender and arthritic joints during the examination were 4.5077 in patients and 4.2462 in control group respectively. The summery of ESR results is mentioned in Table 4.

Among the studied participants, (65\%) had theHLA-DQ8 allele, and $40 \%$ (with or without alleles) had high ESR. However, no significant association was observed between the increased level of ESR and presence of the alleles $(P=0.527)$.
According to our findings, 21 patients who were carriers of the HLA-DQ8 allele (52.5\%) had CRP of equal to or greater than +1 , and $32.4 \%$ of the RA patients with and without the allele were positive for CRP. The CRP results are mentioned in Table 5 .

However, the association between CRP and HLA-DQ8 allele was not statistically significant $(\mathrm{P}=0.505)$.

\section{Discussion}

RA is a progressive, autoimmune, inflammatory disease, which causes the destruction of joint cartilage and bones in its advanced stages [25). Advanced or untreated RA could lead to disability of the patients along with extra-articular manifestations [26].

In the literature, several studies have confirmed the association between the incidence of RA and specific antibodies (e.g., anti-Citrulinated peptide antibodies) in patients who are positive for HLA-DRB1, as well as the majority of the patients withHLA-DR4, HLA-DR1 or both these alleles [27-29]. Recent studies indicate that $D Q$ alleles are significantly associated to RA incident $[30,31)$. Due to the relationship between DR $\beta$ alleles and various alleles belonging to the DQ $\beta 1-\beta 4$ family, especially $D Q 7$ and DQ8, it remains unclear whether these alleles increase susceptibility to RA independently or in combination with other alleles $[32,33]$. This denotes the importance of the prognostic types of these alleles.

Among the studied subjects, females had higher rate of age distribution, which is can be responsible for development of RA [34]. In one study, Drosos et al. (1995) evaluated the clinical, serological and genetic considerations of RA in Greece [35]. According to their findings, there was no significant relationship between DQ alleles and the incidence of RA, which is inconsistent with the results of the present study. This could be due to the differences population of RA in the region of the study. In another research, Massardo (1990) reported no association between the presence of DQ8 alleles and RA incidence, while they stated that DR9 and DR4 serotypes were significantly more frequent in patients compared to the controls [36]. These reports could be due to the significant variations in the inheritance pattern of the alleles in population associated with the development of RA is different.

In one study in this regard, De Veris (2002) reported a significant association between HLA-DQ8 and DQ5 in patients with RA, which is in line with the results of the current study [37]. In Pakistan, Ali et al. (2006) evaluated the frequency of HLA-DQß1 in patients with RA [38] and reported no statistically significant difference between the patients and control group, which is inconsistent with our findings. This could be due to the variations in the ethnicity of the studied subjects. In accordance with the aforementioned studies, Wagner (2003) and Turesson (2005) claimed that HLA-DQ and other serotypes had no impact on the severity and progression of RA [39, 40].

In Iran, the only study focused on the assessment of the relationship between HLA-DQ8 and RA incidence was performed by Tavakol Afshari et al. (2006). According to their findings, RA patients were positive for this allele based on the genetic examination [41]. Correspondingly, they reported that DQ5 and DQ8 were the most dominant HLA-DQB1 alleles associated with higher susceptibility to RA. Moreover, they stated these alleles were possibly correlated with the increased risk of RA and therefore, could be used as molecular markers for the diagnosis this disease. 
According to the results obtained by Laivoranta-Nyman et al. (2004), DQ8 carriers were at a higher risk of developing RA [42]. Among these cases, the association between shared epitope haplotypes and RA incidence was confirmed. These findings are in line with the results of the present study as HLA-DQ8 allele had a higher prevalence among the RA patients compared to control subjects in our sample population.

\section{Conclusion}

According to the results of the present study, there was a significant association between the incidence of RA and presence of the HLA-DQ8 allele which might increase the susceptibility of the patients to RA. However, no significant difference was observed between control group and RA patients in terms of the counts of tender and arthritic joints and raised levels of acute inflammation markers, ESR, and CRP. In conclusion, it is recommended that future studies in this regard be performed on larger sample sizes using more specific inflammation markers in order to find significant correlations between these alleles and development of RA.

\section{Limitations}

We had imitations such as excluding five patients from the study due to diagnoses of other than RA disease, participants with history of genetic, rheumatologic, and autoimmune diseases and those aged less than 16 years were excluded from the study. More specific inflammatory markers should be added to the study to make it much more specific and CRP and ESR should be assessed in larger sample sizes to obtain accurate results.

\section{Authors' Contributions}

All authors contributed equally to this work.

\section{Acknowledgment}

This study was supported by the Student Research Committee of Ahvaz Jundishapur University of Medical Sciences, Ahvaz, Iran. (Project Ref number: U-93145).

\section{Conflicts of interest}

The authors declare no conflict of interest.

\section{Ethical approval}

All procedures performed in studies involving human participants were in accordance with the ethical standards of the institutional and/or national research committee and with the 1964 Helsinki declaration and its later amendments or comparable ethical standards.

\section{References}

1. Walsh NC, Crotti TN, Goldring SR, Gravallese EM. Rheumatic diseases: the effects of inflammation on bone. Immunol Rev 2005; 208: 228-251. https://doi.org/10.1111/i.0105-2896.2005.00338.x.

2. Khurana R, Berney SM. Clinical aspects of rheumatoid arthritis. Pathophysiology 2005; 12(3): 153-165. https://doi.org/10.1016/i.pathophys.2005.07.009.
3. Frisenda S, Perricone C, Valesini G. Cartilage as a target of autoimmunity: a thin layer. Autoimmun Rev 2013; 12(5): 591-598. https://doi.org/10.1016/i.autrev.2012.10.003.

4. Mowla K, Saki MA, Jalali MT, Zayeri ZD. How to manage rheumatoid arthritis according to classic biomarkers and polymorphisms? Front Biol 2017; 12(3): 183-191. https://doi.org/10.1007/s11515-017-1452 4.

5. Padyukov L, Silva C, Stolt P, Alfredsson L, Klareskog L. A geneenvironment interaction between smoking and shared epitope genes in HLA-DR provides a high risk of seropositive rheumatoid arthritis. Arthritis Rheum 2004; 50(10): 3085-3092. https://doi.org/10.1002/art.20553.

6. Seldin MF, Amos Cl, Ward R, Gregersen PK. The genetics revolution and the assault on rheumatoid arthritis. Arthritis Rheum 1999; 42(6): 1071-1079. 0131(199906)42:6<1071::AID-ANR1>3.0.CO;2-8.

7. Janeway CA Jr, Travers P, Walport M, Shlomchik MJ. Immunobiology: The Immune System in Health and Disease. 5th edition. New York, USA Garland Science, 2001. https://www.ncbi.nlm.nih.gov/books/NBK10757.

8. Theofilopoulos AN. The basis of autoimmunity: Part II Genetic predisposition. Immunol Today 1995; 16(3): 150-159. https://doi.org/10.1016/0167-5699(95)80133-2.

9. Weyand CM, Goronzy JJ. Association of $\mathrm{MHC}$ and rheumatoid arthritis. HLA polymorphisms in phenotypic variants of rheumatoid arthritis. Arthritis Res 2000; 2(3): 212-216. https://doi.org/10.1186/ar90.

10. Zanelli E, Breedveld F, de Vries RR. HLA class II association with rheumatoid arthritis: facts and interpretations. Hum immunol 2000 61(12): 1254-1261. https://doi.org/10.1016/S0198-8859(00)00185-3.

11. Glant TT, Finnegan A, Mikecz K. Proteoglycan-induced arthritis: immune regulation, cellular mechanisms, and genetics. Crit Rev Immunol 2003; 23(3): 199-250. https://doi.org/10.1615/CritRevlmmunol.v23.i3.20.

12. Trembath RC, Clough RL, Rosbotham JL, Jones AB, Camp RD, Frodsham $A$, et al. Identification of a major susceptibility locus on chromosome $6 \mathrm{p}$ and evidence for further disease loci revealed by a two stage genome-wide search in psoriasis. Hum Mol Genet 1997; 6(5): 813-820. https://doi.org/10.1093/hmg/6.5.813.

13. Wanstrat A, Wakeland $E$. The genetics of complex autoimmune diseases: non-MHC susceptibility genes. Nat immunol 2001; 2(9): 802 809. https://doi.org/10.1038/ni0901-802.

14. Gregersen PK, Silver J, Winchester RJ. The shared epitope hypothesis. An approach to understanding the molecular genetics of susceptibility to rheumatoid arthritis. Arthritis Rheum 1987; 30(11): 1205-1213. https://doi.org/10.1002/art.1780301102

15. Snir O, Widhe M, von Spee C, Lindberg J, Padyukov L, Lundberg K, et al. Multiple antibody reactivities to citrullinated antigens in sera from patients with rheumatoid arthritis: association with HLA-DRB1 alleles. Ann Rheum Dis 2009; 68(5): 736-743. https://doi.org/10.1136/ard.2008.091355.

16. Van Gaalen FA, van Aken J, Huizinga TW, Schreuder GM, Breedveld FC, Zanelli E, et al. Association between HLA class II genes and autoantibodies to cyclic citrullinated peptides (CCPs) influences the severity of rheumatoid arthritis. Arthritis Rheum 2004; 50(7): 2113 2121. https://doi.org/10.1186/ar1076

17. Wang Z, Metcalf B, Kasheta M, Kasala-Hallinan C, Tran D, Johnson RP, et al. Characterization of MHC class I alleles in sooty mangabeys as a tool for evaluating cellular immunity in natural hosts of SIV infection. Immunogenetics 2015; 67(8): 447-461. https://doi.org/10.1007/s00251-015-0853-2.

18. Balandraud N, Picard C, Reviron D, Landais C, Toussirot E, Lambert N et al. HLA-DRB1 genotypes and the risk of developing anti citrullinated protein antibody (ACPA) positive rheumatoid arthritis. PloS One 2013; 8(5): e64108. https://doi.org/10.1371/journal.pone.0064108.

19. Mackie SL, Taylor JC, Martin SG, Wordsworth P, Steer S, Wilson AG, et al. A spectrum of susceptibility to rheumatoid arthritis within HLA- 
DRB1: stratification by autoantibody status in a large UK population. Genes Immun 2012; 13(2): 120-128. https://doi.org/10.1038/gene.2011.60.

20. Van Steenbergen HW, Raychaudhuri S, Rodríguez-Rodríguez L, Rantapää-Dahlqvist S, Berglin E, Toes RE, et al. Association of valine and leucine at HLA-DRB1 position 11 with radiographic progression in rheumatoid arthritis, independent of the shared epitope alleles but not independent of anti-citrullinated protein antibodies. Arthritis Rheumatol 2015; 67(4): 877-886. https://doi.org/10.1002/art.39018.

21. Raychaudhuri S, Sandor C, Stahl EA, Freudenberg J, Lee H-S, Jia X, et al. Five amino acids in three HLA proteins explain most of the association between MHC and seropositive rheumatoid arthritis. Nat Genet 2012; 44(3): 291-296. https://doi.org/10.1038/ng.1076.

22. Viatte S, Plant D, Raychaudhuri S. Genetics and epigenetics of rheumatoid arthritis. Nat Rev Rheumatol 2013; 9(3): 141-153. https://doi.org/10.1038/nrrheum.2012.237.

23. Chen J, Wright K, Davis JM, Jeraldo P, Marietta EV, Murray J, et al. An expansion of rare lineage intestinal microbes characterizes rheumatoid arthritis. Genome Med 2016; 8(1): 43. https://doi.org/10.1186/s13073016-0299-7.

24. Wolfe F. Comparative usefulness of C-reactive protein and erythrocyte sedimentation rate in patients with rheumatoid arthritis. J Rheumatol 1997; 24(8): 1477-1485. https://www.ncbi.nlm.nih.gov/pubmed/9263138.

25. Genovese MC, Becker J-C, Schiff M, Luggen $M$, Sherrer $Y$, Kremer J, et al. Abatacept for rheumatoid arthritis refractory to tumor necrosis factor $\alpha$ inhibition. N Engl J Med 2005; 353(11): 1114-1123. https://doi.org/10.1056/NEJMoa050524.

26. Szántó S, Bárdos T, Szabó Z, David CS, Buzás El, Mikecz K, et al. Induction of arthritis in HLA-DR4-humanized and HLA-DQ8-humanized mice by human cartilage proteoglycan aggrecan but only in the presence of an appropriate (non-MHC) genetic background. Arthritis Rheum 2004; 50(6): 1984-1995. https://doi.org/10.1002/art.20285.

27. Kulka J. The pathogenesis of rheumatoid arthritis. J Chron Dis 1959; 10(5): 388-402. https://doi.org/10.1016/0021-9681(59)90107-9.

28. Mclnnes IB, Schett $G$. The pathogenesis of rheumatoid arthritis. $N$ Engl J Med 2011; 2205-2219. https://doi.org/10.1056/NEJMra1004965.

29. Weissmann G. The pathogenesis of rheumatoid arthritis. Bull NYU $\begin{array}{llll}\text { Hosp J } & \text { Dis 2006; 64(1-2): }\end{array}$ https://www.ncbi.nlm.nih.gov/pubmed/17121483.

30. Nepom GT, Byers P, Seyfried C, Healey LA, Wilske KR, Stage D, et al. HLA genes associated with rheumatoid arthritis. Identification of susceptibility alleles using specific oligonucleotide probes. Arthritis Rheum 1989; 32(1): 15-21. https://doi.org/10.1002/anr.1780320104.

31. Wordsworth BP, Lanchbury JS, Sakkas LI, Welsh KI, Panayi GS, Bell JI. HLA-DR4 subtype frequencies in rheumatoid arthritis indicate that DRB1 is the major susceptibility locus within the HLA class II region. Proc Natl Acad Sci U S A 1989; 86(24): 10049-10053. https://www.ncbi.nlm.nih.gov/pubmed/2481309.

32. Behrens $M$, Smart M, Luckey $D$, Luthra $H$, Taneja V. To B or not to B: role of $B$ cells in pathogenesis of arthritis in HLA transgenic mice. $J$ Autoimmun 2011; 37(2): 95-103. https://doi.org/10.1016/j.jaut.2011.05.002.

33. Snijders A, Elferink DG, Geluk A, van Der Zanden AL, Vos K, Schreuder GM, et al. An HLA-DRB1-derived peptide associated with protection against rheumatoid arthritis is naturally processed by human APCs. J Immunol 2001; 166(8): 4987-4993. https://doi.org/10.4049/jimmunol.166.8.4987.

34. Jameson JL., Fauci AS, Kasper DL, Hauser SL, Longo DL, Loscalzo J, Harrison's principle of internal medicine. 20th ed. New York: McGrawHill Education, 2018; $4400 \quad$ p. https://accessmedicine.mhmedical.com/book.aspx?bookid=2129.
35. Drosos AA, Moutsopoulos HM. Rheumatoid arthritis in Greece: clinical, serological and genetic considerations. Clin Exp Rheumatol 1995; 13 (Suppl 12): S7-12. https://www.ncbi.nlm.nih.gov/pubmed/8846545.

36. Massardo L, Jacobelli S, Rodriguez L, Rivero S, González A, Marchetti R. Weak association between HLA-DR4 and rheumatoid arthritis in Chilean patients. Ann Rheum Dis 1990; 49(5): 290-292. https://doi.org/10.1136/ard.49.5.290.

37. de Vries N, Tijssen H, van Riel PL, van de Putte L. Reshaping the shared epitope hypothesis: HLA-associated risk for rheumatoid arthritis is encoded by amino acid substitutions at positions 67 to 74 of the HLADRB1 molecule. Arthritis Rheum 2002; 46(4): 921-928. https://doi.org/10.1186/ar466.

38. Ali AA, Moatter T, Baig JA, Iqbal A, Hussain A, Iqbal MP. Polymorphism of HLA-DR and HLA-DQ in rheumatoid arthritis patients and clinical response to methotrexate--a hospital-based study. J Pak Med Assoc 2006; 56(10): 452-456. https://www.ncbi.nlm.nih.gov/pubmed/17144392.

39. Wagner $U$, Kaltenhäuser $S$, Pierer $M$, Seidel W, Tröltzsch $M$, Häntzschel $\mathrm{H}$, et al. Prospective analysis of the impact of HLA-DR and-DQ on joint destruction in recent-onset rheumatoid arthritis. Rheumatology (Oxford) 2003; 42(4): 553-562. https://doi.org/10.1093/rheumatology/keg190.

40. Turesson C, Schaid DJ, Weyand CM, Jacobsson L, Goronzy JJ, Petersson IF, et al. The impact of HLA-DRB1 genes on extra-articular disease manifestations in rheumatoid arthritis. Arthritis Res Ther 2005; 7(6): R1386-1393. https://doi.org/10.1186/ar1837.

41. Tavakkol Afshari J RZ, Shoji-Taheri F, Sadeghizadeh M. The Role of HLA DQB1 Alleles in Susceptibility to Rheumatoid Arthritis. J Rheumatol Suppl 2007; 10: 209-213. http://fsct.modares.ac.ir/article-30-4424en.html.

42. Laivoranta-Nyman S, Möttönen T, Hermann R, Tuokko J, Luukkainen R, Hakala $M$, et al. HLA-DR-DQ haplotypes and genotypes in Finnish patients with rheumatoid arthritis. Ann Rheum Dis 2004; 63(11): 1406 1412. Https://doi.org/10.1136/ard.2003.009969.

\section{Authors:}

Karim Mowla - Rheumatologist, Professor, Golestan Hospital Clinical Research Development Unit, Ahvaz Jundishapur University of Medical Sciences, Ahvaz, Iran. https://orcid.org/0000-0002-7994-7197.

Najmeh Ahmadzadeh Goli - Rheumatology student, Shiraz University of Medical Science, Shiraz, Iran.

Reza Kazemi Nezhad - PhD, Professor, Department of Genetic, Sahid Chamran University of Ahvaz, Ahvaz, Iran. https://orcid.org/0000-00032919-1915.

Zeinab Deris Zayeri - MSc, Golestan Hospital Clinical Research Development Unit, Ahvaz Jundishapur University of Medical Sciences, Ahvaz, Iran. http://orcid.org/0000-0002-8621-5904.

Mehrdad Dargahi Mal-Amir - Rheumatologist, Assistant Professor, Golestan Hospital Clinical Research Development Unit, Ahvaz Jundishapur University of Medical Sciences, Ahvaz, Iran. http://orcid.org/0000-00024449-3359.

Elham Rajaei - Rheumatologist, Assistant Professor, Golestan Hospital Clinical Research Development Unit, Ahvaz Jundishapur University of Medical Sciences, and Ahvaz, Iran. http://orcid.org/0000-0002-8231-0138. 